\title{
ERFURT MALE COHORT STUDY (ERFORT STUDY). STUDY DESIGN AND DESCRIPTIVE RESULTS
}

\author{
Joachim Heinrich ${ }^{1,2}$, Christa Meisinger ${ }^{1}$, Gabriele Wölke ${ }^{1}$, Claudia Greschik ${ }^{1}$, Hubert Schneller ${ }^{1}$, \\ Sabine Brasche ${ }^{2,3}$, Gert Strube ${ }^{2}$ \\ ${ }^{1}$ GSF National Research Center for Environment and Health, Institute of Epidemiology, Neuherberg, Germany \\ ${ }^{2}$ Medical School Erfurt, Department for Preventive Cardiology, Erfurt, Germany \\ ${ }^{3}$ Friedrich-Schiller-University Jena, Institute of Occupational, Social and Environmental Medicine, Department of Indoor Climatology, Jena, \\ Germany
}

\section{SUMMARY}

Objectives: The main objective of ERFORT Study is to investigate cardiovascular risk factors, life-style related factors and psychosocial factors with regard to total and cause-specific mortality and morbidity. This paper describes the study design, frequency data on cardiovascular and psychosocial factors at baseline survey, and findings of three 5 year follow-up medical examinations. Life status was followed for 30 years.

Methods: The Erfurt Male Cohort Study (ERFORT Study) is a population-based prospective cohort study and has its origin in the WHO initiated feasibility study to acquire experience in multi-factorial intervention programs. The baseline survey in 1973-75 examined a random populationbased sample of 1,160 males aged 35-61 years (brutto response rate $74.6 \%$ ) from the city of Erfurt, East Germany.

Results: Standardized and mostly validated methods were applied for a collection of data on cardiovascular risk factors, lifestyle-related and psychosocial factors, blood tests and ECG. Three consecutive follow-up examinations yielded datasets of 907, 740 and 609 subjects' re-examination in 1978-79, 1983-85 and 1988-90. Cardiovascular diseases such as myocardial infarction, angina pectoris, and claudication intermittent approximately doubled within a 15-year follow-up. Prevalence of diabetes strongly increases from $2.8 \%$ at baseline to $12.0 \%$ at the 15 -years follow up. High blood pressure $(\geq 160 / 95 \mathrm{~mm} \mathrm{Hg})$ only slightly increased, whereas the antihypertensive treatment increased from $8.7 \%$ to $33.6 \%$.

Conclusions: This data set of a German cohort followed for several decades is an outstanding database to answer questions about long-term associations between biological and psychosocial factors and mortality in men.

Key words: cohort, men, cardiovascular risk factors, East Germany, life status

Address for correspondence: J. Heinrich, GSF-National Research Center for Environment and Health, Institute of Epidemiology, Ingolstädter Landstraße 1, D-85764 Neuherberg, Germany. E-mail: Joachim.Heinrich@gsf.de

\section{INTRODUCTION}

At the beginning of the 1970 s, the WHO initiated an interregional multicenter cardiovascular screening program under the official title 'Behavioural and Operational Components of Health Intervention Programmes' (1), which was commonly called the 'Kaunas Rotterdam Intervention Study' (KRIS), because this screening program was conducted in the cities Kaunas in Lithuania, and in Rotterdam, The Netherlands. KRIS was a feasibility study to acquire experience in multifactorial intervention and focussed mainly on general methodological problems of intervention studies (2). The objectives and methodological details were described elsewhere (2). Briefly, in each city, a population-based sample of 4,000 males between 45 and 59 years of age were invited for a screening examination in order to select a cohort consisting of men with mildly elevated risk factor levels for cardiovascular diseases. This produced as a one year randomized clinical controlled trial using double blinded methods. Although KRIS was a feasibility study which found positive feasibility results, an extension to a large-scale intervention study was not pursued. KRIS methods (2) were used in a study in the city of Erfurt in the former German Democratic Republic (GDR). Because the KRIS study protocol did not include a common follow-up study, the study conducted in Erfurt had its own follow-up. This study, labelled here as Erfurt Male Cohort Study (ERFORT Study), consists of males living in Erfurt, ideally aged 40-59 at baseline (but really 35-61 years), who were followed for 30 years. There has not yet been any publication on this study in a peer-reviewed journal until 2006, with the exception of a paper by Meisinger et al. (3) on predictivity of disturbed glucose tolerance on long-term mortality. One reason for not publishing any results of this study results from an action of the former German Democratic Republic (GDR). The data of the first two surveys were planned to be published as $\mathrm{PhD}$ thesis of the study's principal investigator. However, he was in prison for one year at the beginning of the 1980 s because he was accused of trying to escape from GDR. After that, he received permission to go to West Germany and therefore had no access to the data and contact with the local research team. Another issue regarding publication was the reduced pressure to publish results in international journals in GDR. It was also difficult to get political permission for publishing data in a journal specifically in an English speaking country. Finally, the Medical School of Erfurt where the ERFORT Study was conducted, was shut down shortly after German re-unification; however, a few departments, including parts of the data holding groups, were transferred and joined departments of the University of Jena. Some files of this study 
were destroyed or lost, but others were archived there and could be used for data re-entry. Therefore, the study design of ERFORT Study and descriptive data on frequencies of cardiovascular risk factors and psychosocial factors of the baseline survey, the three follow-up examinations and the 30 -year life status of participants is described here for the first time.

\section{MATERIAL AND METHODS}

\section{Study Area}

The city of Erfurt, an administrative and a university centre, became the capital of the state Thuringen in 1990. It was the capital of the Erfurt district before 1990. During the past 30 years about 200,000 inhabitants on average lived in the three main city districts: Erfurt-North, Erfurt-City Centre, and Erfurt-South.

\section{Study Design}

The ERFORT Study is a cohort study of men aged $40-59$ years at recruitment. There were three follow-up examinations every five years and the mortality of the cohort was recorded. Figure 1 displays the flow of data collection.

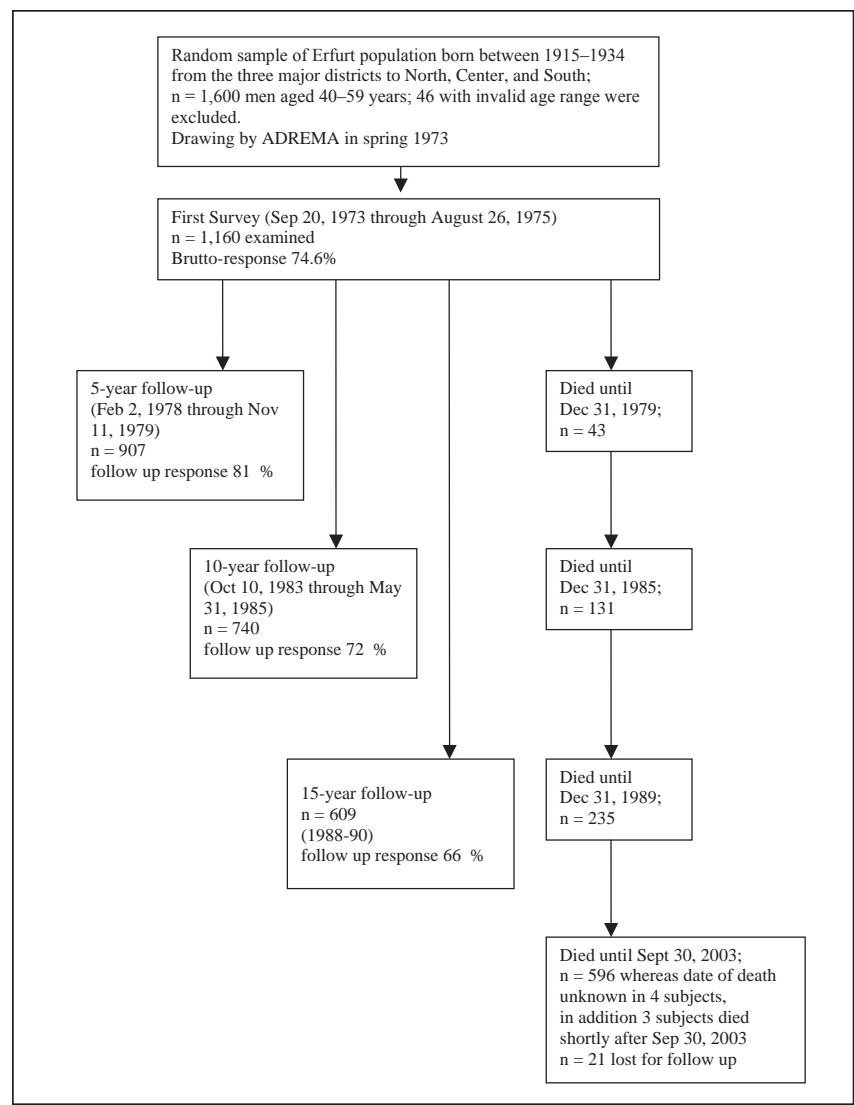

Fig. 1. The Erfurt Male Cohort Study (ERFORT Study) of 1,160 male study participants aged 35-61 years at baseline survey in 1973-75 and follow-up activities.

\section{Study Population}

Using the residential registry and electoral rolls (ADREMA) in spring 1973 a random population sample of 1,600 men was drawn from Erfurt population who lived in the three city districts Erfurt-North, Erfurt-City and Erfurt-South and were born between
1915 and 1934. No exclusion criteria were defined. The first invitation letters were sent out within approximately two years to invite subjects for examination who were between 40 and 59 years old. Those selected subjects who were out of this age range were excluded from the study ( $n=46$, Fig. 1). Because the residential registry was not up to date in that time and obvious errors in date of births occurred, 43 subjects ages ranging from 35-39, and two subjects aged 60 and 61, were invited for the examination and were then also included in the study. Because data of non eligible subjects selected for ERFORT were deleted in 1989, we could not re-construct response rates in relation to eligible subjects. This includes subjects who did not die before invitation to the examination, whose addresses were not incomplete, who had not moved before the examination, who were not permanently or temporarily out of the city, and who did not suffer from a serious chronic disease. The percentages of non-eligible persons were $8.5 \%$ in Kaunas and $3.1 \%$ in Rotterdam (2, p. 33). Therefore, we estimated a substantial higher netto response rate also for Erfurt, if non-eligible subjects were considered.

There were two major deviations from the study protocol of the KRIS study: compared with the original age-range of 45-59 years of the KRIS study, the age range of ERFORT population was extended to $40-44$ years and the size of the study was reduced to 1,600 subjects.

\section{Medical Examinations}

Study subjects were invited to each of the medical examination between $7.00 \mathrm{a} . \mathrm{m}$. and $9.00 \mathrm{a} . \mathrm{m}$. and were asked not to eat or to drink for at least two hours before attending the examination.

\section{Questionnaire Data}

An interview-administered standardized questionnaire was applied with respect to family history, subject's medical history [ROSE's questionnaire on angina pectoris, possible infarction, oedema of legs, dyspnoea and intermittent claudication (4)], on medication use, smoking history (4), alcohol consumption and physical activity (2). Psychosocial data were extensively collected using standardized validated instruments to assess personality traits: Freiburger Persönlichkeitsinventar FPI (5), the Jenkins Activity Survey (JAS) $(6,7,8,9)$, Minnesota Multiphasic Personality Inventory (MMPI) (10), psychic disturbances (PSR, 11), physical and mental complaints scale (BFB, 12) and a detailed psychological questionnaire (see details in 13).

\section{Blood Pressure}

The blood pressure readings were collected with a random zero Sphygmomanometer in a sitting position after 10 minutes unchanged rest. Two readings were averaged (see details in 2, p. A3). We defined hypertensive subjects as having blood pressure values exceeding 160/95 mm Hg $(\geq 160 / 95 \mathrm{~mm} \mathrm{Hg})$ or taking antihypertensive drugs,

\section{Blood Tests}

Blood samples were drawn after fasting for at least two hours preceding the examination.

Total plasma cholesterol was measured according to the HUANG method (14). Plasma glucose was measured by the otoluidine reaction of Hultman, 1959 (15) and Cooper, 1972 (16). Oral glucose tolerance was tested in all non-diabetic subjects. 
The subjects were asked to drink a solution of $75 \mathrm{~g}$ glucose in $200 \mathrm{ml}$ herbal tee. One hour later, a venous blood sample was taken without stasis from one arm of the participant while the participant was sitting upright (3).

\section{Anthropometry}

Height was measured by means of a fixed vertical scale with a crossbar which was placed on top of the head, while the subject stood erect, without shoes, with the heels together and the eyes directed straight ahead. Weight was measured by means of a calibrated level balance, while the subject was wearing just underwear. Skinfolds were measured with Harpenden skinfold callipers. The following skinfolds were measured: midway down the upper arm over the triceps muscle (both left and right) and just below the angle of the scapula (left and right). The sum of all four skinfolds was used as a measure of body fatness. Body mass index was calculated and categorized in underweight $\left(<18.5 \mathrm{~kg} / \mathrm{m}^{2}\right)$, normal $\left(18.5-24.9 \mathrm{~kg} / \mathrm{m}^{2}\right)$, overweight $\left(25.0-29.9 \mathrm{~kg} / \mathrm{m}^{2}\right)$, and obesity ( $\left.\geq 30 \mathrm{~kg} / \mathrm{m}^{2}\right)$ according to WHO recommendation (17).

\section{Electrocardiography}

Resting ECGs were made using 12 standard leads. The Minnesota Code was used to code the ECGs. The observers were specially trained using the WHO standard package of ECGs.

\section{Measurements in Urine}

Glucose, protein, and blood in urine were determined by means of Hemacombistix. The urine sample was requested before the glucose load was given.

\section{Assessment of Life Status}

The life status was assessed by the residential registries. The life status could not be assessed only in four subjects who moved to West Germany before 1989 and in addition in seventeen subjects who were alive in 1989.

\section{Statistical Methods}

Standard descriptive methods were applied here by using SAS 8.2 software (Cary, NC, USA).

\section{RESULTS}

Figure 1 displays the recruitment of 1,160 males (brutto response rates of $74.6 \%$ ) the medical follow-up examinations with re-examination rates of $81 \%$ in $1978-79,72 \%$ in $1983-85$ and $66 \%$ in the $1988-90$ survey each calculated in relation to the living subjects. After a thirty year follow-up until September 30 th, 2003 out of the baseline cohort of 1,160 men, 595 died (three additional subjects after September 30, 2003), 537 were alive and could be traced. The living subjects lived mostly in the city of Erfurt (439), a few had moved outside the city, but lived in East Germany (91), whereas 11 had moved to West Germany. Twenty-one men were lost for follow-up, but they were considered in analyses as alive.

Characteristics of the recruited study participants at the initial medical examination are shown in Table 1.

Psychosocial characteristics, self-assessed health problems, and vital exhaustion are depicted in Table 2 and 3. Frequencies of
Table 1. Characteristics of the ERFORT Study population of 1,160 men aged 35-61 years at baseline survey examined in 1973-75

\begin{tabular}{|c|c|c|}
\hline & $\mathrm{n} / \mathrm{N}$ & $(\%)$ \\
\hline \multicolumn{3}{|l|}{ Age } \\
\hline$<50$ & $690 / 1,160$ & 59.5 \\
\hline$\geq 50$ & $470 / 1,160$ & 40.5 \\
\hline \multicolumn{3}{|l|}{ City district } \\
\hline North & $454 / 1,132$ & 40.1 \\
\hline Center & $315 / 1,132$ & 27.8 \\
\hline South & $363 / 1,132$ & 32.1 \\
\hline \multicolumn{3}{|l|}{ Educational level ${ }^{\S}$} \\
\hline$\leq 8$ grades & $604 / 1,156$ & 52.2 \\
\hline 10 grades & $107 / 1,156$ & 9.3 \\
\hline 11-12 grades & $79 / 1,156$ & 6.8 \\
\hline 13-14 grades & $210 / 1,156$ & 18.2 \\
\hline University & $156 / 1,156$ & 13.5 \\
\hline \multicolumn{3}{|l|}{ Marital status } \\
\hline single & $67 / 1,156$ & 5.8 \\
\hline married/partner & $1,089 / 1,156$ & 94.2 \\
\hline \multicolumn{3}{|l|}{ Smoking habits } \\
\hline never & $187 / 1,159$ & 16.1 \\
\hline former smoker & $330 / 1,159$ & 28.5 \\
\hline current cigarette smoker & $583 / 1,159$ & 50.2 \\
\hline current cigar/pipe smoker & $60 / 1,159$ & 5.2 \\
\hline \multicolumn{3}{|l|}{ Relative weight } \\
\hline underweight $\left(\mathrm{BMI}<18.5 \mathrm{~kg} / \mathrm{m}^{2}\right)$ & $9 / 1,158$ & 0.8 \\
\hline normal (BMI $\left.18.5-<25 \mathrm{~kg} / \mathrm{m}^{2}\right)$ & $386 / 1,158$ & 33.3 \\
\hline overweight (BMI $\left.25-<30 \mathrm{~kg} / \mathrm{m}^{2}\right)$ & $625 / 1,158$ & 54.0 \\
\hline obese $\left(\mathrm{BMI} \geq 30 \mathrm{~kg} / \mathrm{m}^{2}\right)$ & 138/1,158 & 11.9 \\
\hline
\end{tabular}

$\S$ Highest achieved educational level (mostly numbers of completed grades)

Table 2. Psychosocial factor in a population-based sample of 1,160 men aged 35-61 and explored at baseline survey in 1973-75 (ERFORT Study)

\begin{tabular}{|l|c|c|c|}
\hline & AM \pm SD & Median & $\begin{array}{c}25-75 \\
\text { Percentile }\end{array}$ \\
\hline MMPI $(n=1,043)$ & & & \\
\hline Hypochondriasis (HD) $(n=1,043)$ & $8.5 \pm 5.7$ & 7.0 & $4-12$ \\
\hline Dependency (Dy) $(n=1,052)$ & $19.3 \pm 8.4$ & 19.0 & $13-25$ \\
\hline Lie (L) ( $n=1,052)$ & $6.3 \pm 2.8$ & 6.0 & $4-8$ \\
\hline JAS $(n=1,071)$ & & & \\
\hline Total score & $7.0 \pm 3.7$ & 7.0 & $4-9$ \\
\hline FPI (n=1,039) & & & \\
\hline Nervous (FPI 1) $(n=1,029)$ & $4.9 \pm 3.2$ & 5.0 & $2-7$ \\
\hline Aggressive (FPI 2) $(n=1,029)$ & $2.3 \pm 2.0$ & 2.0 & $1-3$ \\
\hline Depressive (FPI 3) $(n=1,029)$ & $3.9 \pm 2.9$ & 3.0 & $2-6$ \\
\hline Irritable (FPI 4) $(n=1,029)$ & $4.3 \pm 2.6$ & 4.0 & $2-6$ \\
\hline Sociable (FPI 5) $(n=1,028)$ & $7.3 \pm 2.5$ & 7.0 & $6-9$ \\
\hline Patient (FPI 6) $(n=1,029)$ & $4.1 \pm 1.7$ & 4.0 & $3-5$ \\
\hline Dominating (FPI 7) $(n=1,029)$ & $3.9 \pm 2.2$ & 4.0 & $2-5$ \\
\hline Inhibited (FPI 8) $(n=1,029)$ & $3.7 \pm 2.4$ & 4.0 & $2-5$ \\
\hline Open minded (FPI 9) $(n=1,029)$ & $8.0 \pm 3.2$ & 8.0 & $6-10$ \\
\hline Extraverted (FPI-E) $(n=1,029)$ & $5.8 \pm 2.4$ & 6.0 & $4-8$ \\
\hline Labile (FPI-N) $(n=1,029)$ & $4.1 \pm 2.4$ & 4.0 & $2-6$ \\
\hline Masculine (FPI-M) $(n=1,025)$ & $5.5 \pm 1.9$ & 6.0 & $4-7$ \\
\hline
\end{tabular}

${ }^{\S} \mathrm{AM}$ arithmetric mean, SD standard deviation 
Table 3. Self-assessed health symptoms/complaints (BFB) (a) and vital exhaustion (b) in a population-based sample of 1,160 men aged 35-61 and explored at baseline survey in 1973-75 (ERFORT Study)

\begin{tabular}{|c|c|c|c|c|c|}
\hline a) Health Symptoms/Complaints (BFB) & None & \multicolumn{2}{|c|}{ A few (1-2) } & \multicolumn{2}{|c|}{ Frequent complaints } \\
\hline Cardiovascular (BFB 1) $(n=1,112)$ & 30.2 & \multicolumn{2}{|c|}{37.4} & \multicolumn{2}{|r|}{32.4} \\
\hline Parasympathic CV (BFB 2) $(n=1,111)$ & 46.0 & \multicolumn{2}{|c|}{42.9} & \multicolumn{2}{|r|}{11.1} \\
\hline Stomach and gut (BFB 3) $(n=1,111)$ & 66.6 & \multicolumn{2}{|c|}{28.3} & \multicolumn{2}{|r|}{5.1} \\
\hline Airways (BFB 4) $(n=1,112)$ & 62.5 & \multicolumn{2}{|c|}{33.4} & \multicolumn{2}{|r|}{4.1} \\
\hline Skeletal (BFB 5) $(n=1,112)$ & 58.4 & \multicolumn{2}{|c|}{41.5} & \multicolumn{2}{|r|}{0.1} \\
\hline Sexual-related disturbances (BFB 6) $(n=1,112)$ & 82.1 & \multicolumn{2}{|c|}{17.5} & \multicolumn{2}{|r|}{0.5} \\
\hline Phobic symptoms (BFB 7) $(n=1,112)$ & 6.7 & \multicolumn{2}{|c|}{17.7} & \multicolumn{2}{|r|}{75.6} \\
\hline Depressive symptoms (BFB 8) $(n=1,112)$ & 53.8 & \multicolumn{2}{|c|}{35.7} & \multicolumn{2}{|r|}{10.5} \\
\hline b) Vital exhaustion & $\begin{array}{c}\text { Very often } \\
\%\end{array}$ & $\begin{array}{l}\text { Often } \\
\%\end{array}$ & & & $\begin{array}{c}\text { Not at all } \\
\%\end{array}$ \\
\hline Tense and nervous $(n=1,062)$ & 20.8 & 29.4 & & & 21.8 \\
\hline No worries about job $(n=1,061)$ & 13.9 & 15.9 & & & 39.5 \\
\hline Exhausting daily work $(n=1,060)$ & 29.5 & 39.5 & & & 8.3 \\
\hline No tension in family relations $(n=1,055)$ & 52.4 & 24.6 & & & 10.8 \\
\hline Strong nervous strain in daily work $(n=1,060)$ & 43.6 & 28.8 & & & 10.1 \\
\hline Frequent tensions in relationship to other persons $(n=1,061)$ & 3.7 & 9.7 & & & 48.1 \\
\hline Total mentally and physically exhausted at the end of the day $(n=1,061)$ & 9.3 & 32.6 & & & 20.7 \\
\hline
\end{tabular}

selected major chronic diseases are displayed in Table 4. Details on frequencies of psychological characteristics and in relation to blood pressure, smoking and impaired glucose tolerance were presented in the unpublished thesis by the Co-PI of the ERFORT Study Michael Geyer in 1977 (13).

Temporal changes of blood pressure levels and blood test results are given in Table 5. Average systolic blood pressure levels substantially increase within the 15-year follow-up from 138.3 to $144.2 \mathrm{~mm} \mathrm{Hg}$, whereas average diastolic blood pressure remained unchanged within this time period ( 88.7 to $87.9 \mathrm{~mm}$ $\mathrm{Hg}$ ). Furthermore, $8.7 \%$ of the study population were treated with antihypertensive drugs at baseline survey, 33.6 \% 15 years later. The prevalence rates of hypertension increased from $30.7 \%$ at baseline survey to $46.8 \% 15$ years later. The mean cholesterol levels increased from 199 to $245 \mathrm{mg} / \mathrm{dl}$ within the 15-year follow-up period.

The survival probability for $5,10,15,20,25$, and 30 years are $97 \%, 91 \%, 81 \%, 70 \%, 57.3 \%$ and $45 \%$.

In order to assess potential participation bias, study characteristics and cardiovascular risk factor levels at baseline survey were compared among participants, living non-participants and dead cohort members (Table 6). Subjects who died during the first five or ten years of the follow up were older, less educated, fewer never smokers, were more frequently underweight, more commonly hypertensive and showed more common 1-hour post-load hyperglycemia. The mean cholesterol levels were not substantially different between dead and living subjects. The distribution of characteristics in the non-participating but living subjects was also

Table 4. Selected chronic diseases in ERFORT Study population of 1,160 men aged 35-61 years examined in 1973-75

\begin{tabular}{|c|c|c|c|c|c|c|c|c|}
\hline & \multicolumn{2}{|c|}{$\begin{array}{l}\text { Baseline } \\
1973-75\end{array}$} & \multicolumn{2}{|c|}{5 years } & \multicolumn{2}{|c|}{10 years } & \multicolumn{2}{|c|}{15 years } \\
\hline & $\mathrm{n} / \mathrm{N}$ & $\%$ & $\mathrm{n} / \mathrm{N}$ & $\%$ & & $\%$ & & $\%$ \\
\hline \multicolumn{9}{|l|}{ Cardiovascular diseases } \\
\hline Myocardial infarction ${ }^{\S}(\mathrm{MI})$ & $48 / 1,150$ & 4.2 & $66 / 903$ & 7.3 & $42 / 496$ & 8.5 & $54 / 810$ & 8.9 \\
\hline Silent $\left.\mathrm{M}\right|^{\S \S}$ & $9 / 1,146$ & 0.8 & $11 / 905$ & 1.2 & $13 / 487$ & 2.7 & & \\
\hline Angina pectoris ${ }^{\$}(\mathrm{AP})$ & $94 / 1,064$ & 8.8 & $112 / 906$ & 12.4 & $93 / 737$ & 12.6 & $112 / 608$ & 18.4 \\
\hline Claudication intermittent $(\mathrm{Cl})^{\$}$ & $24 / 1,157$ & 2.1 & $29 / 906$ & 3.2 & $31 / 737$ & 4.2 & $28 / 607$ & 4.6 \\
\hline High blood pressure $^{+}$ & $323 / 1,160$ & 27.8 & $212 / 906$ & 23.4 & $303 / 736$ & 41.2 & $194 / 607$ & 32.0 \\
\hline \multicolumn{9}{|l|}{ Metabolic diseases } \\
\hline Diabetes mellitus & $33 / 1,160$ & 2.8 & $40 / 907$ & 4.4 & $62 / 739$ & 8.4 & $73 / 609$ & 12.0 \\
\hline 1-hour post-load hyperglycemia ${ }^{++}$ & $126 / 1,107$ & 11.4 & & & & & & \\
\hline Elevated total cholesterol $(\geq 216 \mathrm{mg} / \mathrm{dl})$ & $350 / 1,159$ & 30.2 & $645 / 904$ & 71.4 & $525 / 728$ & 72.1 & $434 / 606$ & 71.6 \\
\hline
\end{tabular}

${ }^{\S}$ Doctor diagnosis according to medical history

\$\$ Minnesota codes 1.1 or 1.2 and no doctor diagnosis

$\$$ Typical according to ROSE's questionnaire

+ $\mathrm{BP} \geq 160 / 95 \mathrm{~mm} \mathrm{Hg}$

${ }^{++}$Glucose $>200 \mathrm{mg} / \mathrm{dl} 1$ hour after a $75 \mathrm{~g}$ glucose load 
Table 5. Temporal changes of blood pressure levels and blood test results in men during three consecutive 5-year follow-up periods

\begin{tabular}{|c|c|c|c|c|c|}
\hline & $\begin{array}{l}\text { Blood pressure } \\
\text { systolic } \\
X \pm S D\end{array}$ & $\begin{array}{l}\text { Blood pressure } \\
\text { diastolic } \\
x \pm S D\end{array}$ & $\begin{array}{c}\text { Antihypertensive } \\
\text { treatment } \\
\%\end{array}$ & $\begin{array}{c}\text { Hypertension } \S \\
\%\end{array}$ & $\begin{array}{c}\text { Total cholesterol } \\
x \pm \text { SD }\end{array}$ \\
\hline $\begin{array}{l}\text { Baseline 1973-75 } \\
n=1,160\end{array}$ & $\begin{array}{c}138.3 \pm 20.0 \\
(n=1,160)\end{array}$ & $\begin{array}{l}88.7 \pm 10.6 \\
(n=1,160)\end{array}$ & $\begin{array}{c}8.7 \\
(n=1,158)\end{array}$ & $\begin{array}{c}30.7 \\
(n=1,158)\end{array}$ & $\begin{array}{c}199.0 \pm 38.6 \\
(n=1,159)\end{array}$ \\
\hline $\begin{array}{l}\text { 5-year follow-up 1978-79 } \\
n=907\end{array}$ & $\begin{array}{c}138.1 \pm 20.5 \\
(n=906)\end{array}$ & $\begin{array}{c}84.8 \pm 11.8 \\
(n=906)\end{array}$ & $\begin{array}{c}12.5 \\
(n=904)\end{array}$ & $\begin{array}{c}29.7 \\
(n=904)\end{array}$ & $\begin{array}{c}244.9 \pm 50.0 \\
(n=904)\end{array}$ \\
\hline $\begin{array}{l}\text { 10-year follow-up 1983-85 } \\
n=740\end{array}$ & $\begin{array}{c}148.1 \pm 21.0 \\
(n=736)\end{array}$ & $\begin{array}{c}91.8 \pm 11.6 \\
(n=736)\end{array}$ & $\begin{array}{c}23.6 \\
(n=737)\end{array}$ & $\begin{array}{c}49.3 \\
(n=733)\end{array}$ & $\begin{array}{l}251.0 \pm 52.4 \\
(n=728)\end{array}$ \\
\hline $\begin{array}{l}\text { 15-year follow-up 1988-90 } \\
n=609\end{array}$ & $\begin{array}{c}144.2 \pm 20.6 \\
(n=608)\end{array}$ & $\begin{array}{c}87.9 \pm 10.0 \\
(n=608)\end{array}$ & $\begin{array}{c}33.6 \\
(n=608)\end{array}$ & $\begin{array}{c}46.8 \\
(n=609)\end{array}$ & $\begin{array}{c}244.6 \pm 45.1 \\
(n=606)\end{array}$ \\
\hline
\end{tabular}

$\S$ Blood pressure above 160/95 mm Hg or antihypertensive treatment

$\mathrm{SD}=$ Standard Deviation

different from participants' characteristics, but less pronounced than the differences between dead and living subcohorts. Therefore, non-participation could not be considered as random. Briefly, subjects with a higher cardiovascular risk tended to refuse study participation or to be lost due to premature death.

\section{DISCUSSION}

The ERFORT Study is one of the most longstanding population-based cohort studies in Germany. For several reasons this study has outstanding data quality and future analyses of this unique data set will show promising results. Although the methods used at the baseline survey were developed at the early 1970s, these standardized questionnaire-based instruments currently represent the state of the art. This holds true for the standard questionnaire on angina pectoris, potential myocardial infarction and claudication intermittens developed by one of the fathers of Cardiovascular Epidemiology, Geoffrey Rose (4). These instruments are still used in currently ongoing international studies $(18,19)$.

Also the recommended questionnaires on smoking, alcohol consumption and physical activity published in the standard book on Cardiovascular Survey Methods (4) were applied to the base-

Table 6. Potential participation bias by a non-random participation in follow-up examinations

\begin{tabular}{|c|c|c|c|c|c|c|}
\hline \multirow{2}{*}{$\begin{array}{l}\text { Characteristics at baseline } \\
\text { examination }\end{array}$} & \multicolumn{3}{|c|}{ Participation in 5-year follow-up } & \multicolumn{3}{|c|}{ Participation in 10-year follow-up } \\
\hline & yes & no and alive & died & yes & no and alive & died \\
\hline$N(\%)^{\S}$ & $907 *(78 \%)$ & $216(19 \%)$ & $37(3 \%)$ & $740 * \star(64 \%)$ & $304(26 \%)$ & $116(10 \%)$ \\
\hline Age (mean, years) & 47.8 & 48.4 & 52.5 & 47.6 & 47.8 & 51.5 \\
\hline \multicolumn{7}{|l|}{ Education } \\
\hline$\leq 8$ grades & $457 / 904(50.6 \%)$ & $125 / 215(58.1 \%)$ & $22 / 37(59.5 \%)$ & $366 / 739(49.5 \%)$ & $172 / 302(57.0 \%)$ & $66 / 115(57.4 \%)$ \\
\hline$>8$ grades & $447 / 904(49.4 \%)$ & $91 / 215(41.9 \%)$ & $15 / 37(40.5 \%)$ & $373 / 739(50.5 \%)$ & $130 / 302(43.0 \%)$ & $49 / 115(42.6 \%)$ \\
\hline \multicolumn{7}{|l|}{ Smoking } \\
\hline never & $154 / 906(17.0 \%)$ & $29 / 216(13.4 \%)$ & $4 / 37(10.8 \%)$ & $133 / 740(18.0 \%)$ & $45 / 303(14.9 \%)$ & $9 / 116(7.8 \%)$ \\
\hline former smoker & $273 / 906(30.1 \%)$ & $47 / 216(21.8 \%)$ & $10 / 37(27.0 \%)$ & $228 / 740(30.8 \%)$ & $67 / 303(22.1 \%)$ & $35 / 116(30.2 \%)$ \\
\hline current smoker & $479 / 906(52.9 \%)$ & $140 / 216(64.8 \%)$ & $23 / 37(62.2 \%)$ & $379 / 740(51.2 \%)$ & $191 / 303(63.0 \%)$ & $72 / 116(62.0 \%)$ \\
\hline \multicolumn{7}{|l|}{ Relative weight } \\
\hline underweight $\left(\mathrm{BMI}<18.5 \mathrm{~kg} / \mathrm{m}^{2}\right)$ & $3 / 905(0.3 \%)$ & $2 / 216(0.9 \%)$ & $4 / 37(10.8 \%)$ & $4 / 740(0.5 \%)$ & $1 / 304(0.3 \%)$ & $4 / 114(3.5 \%)$ \\
\hline normal (BMl $\left.18.5-<25 \mathrm{~kg} / \mathrm{m}^{2}\right)$ & $293 / 905(32.4 \%)$ & $78 / 216(35.1 \%)$ & $15 / 37(40.6 \%)$ & $236 / 740(31.9 \%)$ & $113 / 304(37.2 \%)$ & $37 / 114(32.5 \%)$ \\
\hline overweight (BMI $25-<30 \mathrm{~kg} / \mathrm{m}^{2}$ ) & $507 / 905(56.0 \%)$ & $105 / 216(48.6 \%)$ & $13 / 37(35.1 \%)$ & $418 / 740(56.5 \%)$ & $150 / 304(49.3 \%)$ & $57 / 114(50.0 \%)$ \\
\hline obese $\left(\mathrm{BMl} \geq 30 \mathrm{~kg} / \mathrm{m}^{2}\right)$ & $102 / 905(11.3 \%)$ & $31 / 216(14.4 \%)$ & $5 / 37(13.5 \%)$ & $82 / 740(11.1 \%)$ & $40 / 304(13.2 \%)$ & $16 / 114(14.0 \%)$ \\
\hline \multicolumn{7}{|l|}{ Blood pressure } \\
\hline systolic (mean) & 137.3 & 140.7 & 150.2 & 136.1 & 140.1 & 147.9 \\
\hline diastolic (mean) & 88.4 & 89.3 & 92.0 & 87.9 & 89.6 & 91.6 \\
\hline hypertension & $258 / 907(28.5 \%)$ & $79 / 216(36.6 \%)$ & $19 / 37(51.4 \%)$ & $194 / 740(26.2 \%)$ & $109 / 304(35.9 \%)$ & $53 / 116(45.7 \%)$ \\
\hline Total cholesterol (mg/dl) (mean) & $198.4^{2}$ & 202.9 & 191.1 & $198.3^{3}$ & 199.6 & 201.9 \\
\hline $\mathrm{IGT}^{+}(>200 \mathrm{mg} / \mathrm{dl})$ & $92 / 866(10.6 \%)$ & $30 / 208(14.4 \%)$ & $4 / 33(12.1 \%)$ & $71 / 707(10.0 \%)$ & $34 / 294(11.6 \%)$ & $21 / 106(19.8 \%)$ \\
\hline
\end{tabular}

${ }^{\S}$ Absolute and relative numbers for withdraws (no participation and alive) and died subjects might be different from that shown in Figure 1 because time frames were slightly different.

*7 died until Dec. 31, 1979; ** 16 died until Dec. 31, 1985; ${ }^{2}$ n=906; ${ }^{3}$ n=739; + IGT = Impaired Glucose Tolerance 
line survey. These methods are considered as valid instruments in epidemiology nowadays. However, the ERFORT Study has the clear limitation of the cardiovascular focus.

The ERFORT Study shares a major limitation with several other cardiovascular risk factor studies of the 1960s and 1970s, such as for example the Goteborg Study and the Seven Countries Study $(20,21)$ : the restriction to men.

The medical examination including blood pressure measurements and highly standardized coding of ECG changes according to the Minnesota coding also followed recommendations which are similar to the codings today (4). Already 30 years ago ERFORT Study was conducted according a written study manual (1), which was carefully translated into German and typed in 30 copies for the field workers. Today one would label these materials as standard operating procedures (SOP's). External experts (Ed Dowd, Pekka Puska, Dusan Grafnetter) assured the quality of the field work by site visits. The baseline survey remained the same and the core questionnaires and methodology on blood pressure measurement and ECG recording were not modified within the follow-up examinations. In the ERFORT Study an increase in the prevalence and treatment of hypertension was observed between 1973/75 and 1990. Comparable results were reported from other German studies between the eighties and nineties (22). However, the lab work could not be kept unchanged over the time. Equipment, methods and technicians had changed over time. Blood test results are affected by changed analytical methods (23). Change of blood test levels over time is a result of the combined effect of changed methods and growing age. The changes in blood measurements are the most severe limitations of this study as in other cohort studies with a follow-up of several decades.

A strength which makes ERFORT Study unique is the comprehensive involvement of psychological and psychosocial inventories, again mostly validated and standardized shortly before beginning the field work. The basic papers for FPI, and JAS, and BFB were published only one to three years before launching the baseline survey. Although the initial PI could only supervise the cohort until 1980, the successing PI and several other members of the study teams including all study nurses were steadily involved in all of the four surveys.

A further strength of ERFORT Study is the fairly high participation rate at the baseline survey and high re-examination rate of $66 \%$ also 15 years later. The numbers of lost due to follow-up until 1989 were extremely low. Only four subjects could not be traced until 1989. Also after German re-unification the life status of only 21 participants including the four subjects could not be gathered. With exception of those few people the life status of this 30 year follow-up cohort could be determined.

We concluded that the data of ERFORT Study revealed excellent data quality. This outstanding data base will answer questions on very long-term associations between biological and psychosocial factors and mortality in men. Thus, the ERFORT Study constitutes a valuable extension to other population-based German studies (24-27).

\section{Acknowledgement}

The professional fieldwork during two decades is deeply acknowledged. The representatives of the study physicians are PD Dr. Hartmut Holtz and PD Dr. Klaus-Dieter Dück, who examined together with the PI (G. S.) of the study a large fraction of the study populations and who were involved also in the follow-up programs. The blood tests were conducted by supervision of Prof. Dr. Peter Koehler. The program on psychosocial factors were supervised and conducted by Prof. Dr. M. Geyer, Dr. E. Kunzendorff, Edeltraud Bartel, Klaus Andrzejak, Dr. Katja Limpert, Dr. Günter Stübe, and Helma Bürger. Furthermore, we thank the study nurses Margrit Ullmann, Margot Langelotz, Anke Binding, and Siglinde Litzrodt as well as the team assistant Margret Remke and data manager Elke Siegemund, and Terinka Baldwin for their extremely cautious work. The editing work by Marie Cox and the writing of the manuscript by Gina Gillig are much appreciated. The authors acknowledge the institutional support of the directors of the department of the Erfurt Medical School, Department for Preventive Cardiology, Prof. Dr. Joachim Knappe, and of the GSF-Institute of Epidemiology, Prof. Dr. Dr. H.-Erich Wichmann.

\section{REFERENCES}

1. Behavioural and Operational Components of Health Intervention Programmes. Geneva: WHO; 1972.

2. Glasunov IS, Dowd JE, Baubiniene AV, Grabauskas V, Sturmans F, Schuurman JH, editors. The Kaunas Rotterdam Intervention Study. Amsterdam: Elsevier/North-Holland Biomedical Press; 1981.

3. Meisinger C, Wolke G, Brasche S, Strube G, Heinrich J. Postload plasma glucose and 30-year mortality among nondiabetic middle-aged men from the general population: the ERFORT Study. Ann Epidemiol. 2006 Jul;16(7):534-9.

4. Rose GA, Blackburn H. Cardiovascular survey methods. Monograph series no. 56. Geneva: WHO; 1968.

5. Fahrenberg J, Selg H. The Freiburg Personality Inventory. Göttingen: Hogrefe; 1970. (In German.)

6. Jenkins CD, Zyzanski SJ, Rosenman RH, Cleveland GL. Association of coronary-prone behaviour scores with recurrence of coronary heart disease. J Chronic Dis. 1971 Nov;24(10):601-11.

7. Jenkins CD, Zyzanski SJ, Rosenman RH. Progress toward validation of a computer-scored test for the type A coronary-prone behaviour pattern. Psychosom Med. 1971 May-Jun;33(3):193-202.

8. Jenkins CD. Psychologic and social precursors of coronary disease. N Engl J Med. 1971 Feb 11;284(5):244-55. Part 2 in: N Engl J Med. 1971 Feb 11;284(6):307-17.

9. Appels A, Mulder P, van't Hof M, Jenkins CD, van Houtem J, Tan F. A prospective study of the Jenkins Activity Survey as a risk indicator for coronary heart disease in the Netherlands. J Chronic Dis. 1987;40(10):95965.

10. Spreen O. MMPI-Saarbrücken. In: Hathaway SR, McKinley JC. Manual of the German issue of the Minnesota Personality Inventory. Bern: Verlag Hans Huber; 1963. (In German.)

11. Stübe G, Herrmann A, Geyer M, Knappe J. First results of a psychometric inventory to assess „psycho-social“ risk factors for the pathogenesis of cardio-vascular diseases. Dtsch Gesundheitsw. 1975;30:1028-30. (In German.)

12. Höck K, Hess H. Assessment of neuroses by means of questionnaires. In: Rösler HD, Schmidt HD, Szewczyk H, editors. Diagnosis of personality. Berlin: Verlag der Wissenschaften; 1970. (In German.)

13. Geyer M. Psychosocial traits in high risk subjects for myocardial infarction-investigation of an urban male population aged 40-59 years [dissertation]. Erfurt: 1977. (In German.)

14. Huang TC, Chen CP, Wefler V, Raftery A. A stable reagent for the Liebermann-Burchard reaction. Application to rapid serum cholesterol determination. Anal Chem. 1961;33(10):1405-7.

15. Hultman E. Rapid specific method for determination of aldosaccharides in body fluids. Nature. 1959 Jan 10;183(4654):108-9.

16. Cooper KH. Training of physical activity. Stuttgart: Fischer; 1972. (In German.)

17. Obesity: preventing and managing the global epidemic. Report of a WHO consultation. World Health Organ Tech Rep Ser. 2000;894:i-xii, 1-253.

18. Oei HH, Vliegenthart R, Deckers JW, Hofman A, Oudkerk M, Witteman JC. The association of Rose questionnaire angina pectoris and coronary calcification in a general population: the Rotterdam Coronary Calcification Study. Ann Epidemiol. 2004 Jul;14(6):431-6. 
19. Dieter RS, Biring T, Tomasson J, Gudjonsson T, Brown RL, Vitcenda M, et al. Classic intermittent claudication is an uncommon manifestation of lower extremity peripheral arterial disease in hospitalized patients with coronary artery disease. Angiology. 2004 Nov-Dec;55(6):625-8.

20. Harmsen P, Lappas G, Rosengren A, Wilhelmsen L. Long-term risk factors for stroke: twenty-eight years of follow-up of 7457 middle-ageed men in Goteborg, Sweden. Stroke. 2006 Jul;37(7):1663-7.

21. Lanti M, Menotti A, Nedeljkovic S, Nissinen A, Kafatos A, Kromhout D. Long-term trends in major cardiovascular risk factors in cohorts of aging men in the European cohorts of the Seven Countries Study. Aging Clin Exp Res. 2005 Aug;17(4):306-15.

22. Laaser U, Breckenkamp J. Trends in risk factor control in Germany 1984 1998: high blood pressure and total cholesterol. Eur J Public Health. 2006 Apr;16(2):217-22.

23. Sundvall J, Leiviska J, Alfthan G, Vartiainen E. Serum cholesterol during 27 years: assessment of systematic error and affecting factors and their role in interpreting population trends. Clin Chim Acta. 2007 Mar;378(12):93-8.
24. John U, Greiner B, Hensel E, Ludemann J, Piek M, Sauer S, et al. Study of Health In Pomerania (SHIP): a health examination survey in an east German region: objectives and design. Soz Praventivmed. 2001;46(3):18694.

25. Löwel H, Döring A, Schneider A, Heier M, Thorand B, Meisinger C MONICA/KORA Study Group. The MONICAAugsburg surveys - basis for prospective cohort studies. Gesundheitswesen. 2005 Aug;67 Suppl 1: S13-8.

26. Thefeld W, Stolzenberg H, Bellach BM. The Federal Health Survey: response, composition of participants and non-responder analysis. Gesundheitswesen. 1999 Dec;61 Spec No: S57-61. (In German.)

27. Stang A, Moebus S, Dragano N, Beck EM, Mohlenkamp S, Schmermund A, et al; Heinz Nixdorf Recall Study Investigation Group. Baseline recruitment and analyses of nonresponse of the Heinz Nixdorf Recall Study: identifiability of phone numbers as the major determinant of response. Eur J Epidemiol. 2005;20(6):489-96.

Received September 4, 2006 Received and accepted in revised form February 12, 2007 